Nachrufe

\title{
Maria Luisa Righini Bonelli
}

\author{
Von Maria Celeste Cantù
}

Maria Luisa Righini Bonelli, university Professor of the History of Science was Director of the Institute and Museum of the History of Science in Florence from 1942 to the 18th of December 1981, day of her death.

The remarkable development of the Museum collections, their arrangement and setting, the brief gathering and cataloguing of important historic and scientific books, the lasting establishment on an international level of an institution that had had a modest beginning with few funds is due to her competent and disinterested enthusiasm.

Maria Luisa Righini Bonelli's assistance at the time of the flood, her services in salvaging and repairing the instruments reduced to disastrous conditions are not to be forgotten.

During her career she collaborated with a number of important and specialized journals: from 1943 to 1956 at the Direction of the «Rivista di Storia delle Scienze Mediche e Naturali»; from 1959 to 1978 she was a member of the editorial staff of the International Review of the History of Science «Physis», founded by her; in 1976 she founded and subsequently directed the «Annali dell'Istituto e Museo di Storia della Scienza di Firenze», now in its fifth year of life.

From 1942 onwards she promoted and organized national and international Congresses for the History of Science, and attended to the editing of the proceedings.

She was invited abroad for scientific consultations and lectures, in particular in Holland, Denmark, Poland (Warsaw-Cracov), Sweden, England, Germany (Münich), Persia, Siria (Damascus-Aleppo), Lebanon (Beyrut), the United States of America, Japan, Mexico, Peru and Amsterdam.

She organized historic scientific exhibitions in Italy and abroad and was a Correspondent member of important institutions, among which: Deputazione di Storia Patria per gli Abruzzi; l'Accademia di Storia dell'Arte Sanitaria; Honorary Member of the Associazione Italiana di Storia della Farmacia. 
On July 13, 1965, she was appointed honorary Inspector for the Research and Preservation of historic and scientific documents for the Province of Florence; later the appointment was extended to all Italy. Prof. Righini Bonelli hence devoted herself to seeking scientific material of historical value and requested, often with success, that the objects found be definitively assigned to the Museum of the History of Science so as to guarantee their perfect preservation and display.

Widespread and important are the acknowledgments she received from international Institutions for the History of Science and Scientific Instruments: Vice-President of the International Union of the History and Philosophy of Science and member of the Académie Internationale d'Histoire des Sciences; member of the Commission for the World Inventory of Scientific Apparatus of historical interest; member of the Commission of World Bibliography of the Union Internationale d'Histoire et Philosophie des Sciences; member of the Genooschap vor Gesschiedenis der Geneskunde Wiskunde en Natuurweterschappen of Amsterdam; Chief consultant at the General Direction of the Naval Medical Corps for the History of Science; Consultant for Italy of the Dictionary of: Scientific Biography of the American Council of Learned Societies; Counsellor from 1954 of the Italian Group of the History of Science, of which for a long time she was Secretary.

She organized the Exhibition of Galileo's documents and instruments at the Central National Library of Florence (September 9 - October 11, 1964), and the Symposium on the history of Galilean Science (September 14-16, 1964). For the Exhibition she prepared an annotated Catalogue.

Maria Luisa Righini Bonelli was awarded many medals: the gold medal of merit for School, Culture and Art (July 22, 1967); gold medal of the Order of Pharmacists (July 30, 1967); gold medal of the Medical Corps; gold medal from Women Rotary Club (1967); the Sarton Medal (1979) as acknowledgment of her many and valuable contributions to the History of Science and of scientific instruments that amount to 160 publications.

Dr. Maria Celeste Cantù

Conservatore

Istituto e Museo di Storia della Scienza

Piazza dei Giudici, 1

I-50122 Firenze 